\title{
Chinese Mathematics Teaching Reform Based on the Guidance of Core Literacy
}

\author{
Zhikui Hu \\ Jinhua Foreign Language School of Zhejiang Province, Jinhua, China \\ Email:hzk2019112020@163.com
}

How to cite this paper: Hu, Z. K. (2019). Chinese Mathematics Teaching Reform Based on the Guidance of Core Literacy. Creative Education, 10, 3410-3419. https://doi.org/10.4236/ce.2019.1013263

Received: November 23, 2019

Accepted: December 17, 2019

Published: December 20, 2019

Copyright $\odot 2019$ by author(s) and Scientific Research Publishing Inc. This work is licensed under the Creative Commons Attribution International License (CC BY 4.0).

http://creativecommons.org/licenses/by/4.0/

\section{c) (i) Open Access}

\begin{abstract}
Core accomplishment is the essential character and key ability that students should have to adapt to the needs of lifelong development and social development. Since the reform and opening up in China, the curriculum objectives have undergone three important changes, from the "double-base" curriculum objectives that emphasize basic knowledge and basic skills, to the "three-dimensional goals" that emphasize knowledge and ability, process and method, and emotional attitude values, to the curriculum reform based on core literacy. Each reform reflects China's reflection on the reform of basic education and the consideration on what kind of talents to cultivate. However, the current situation of education is still in the transitional stage from knowledge imparting to ability cultivation. It is important to develop students' core literacy and give full play to the function of discipline education, which points out the direction for the reform of the mathematics curriculum in China. It is necessary to clarify the background of curriculum reform and the connotation of mathematics core accomplishment, and discuss the strategy of mathematics curriculum reform and the change of teaching mode under the guidance of core accomplishment, so as to make beneficial exploration and important supplement for China's mathematics teaching reform.
\end{abstract}

\section{Keywords}

Core Literacy, Mathematics, Curriculum Reform

\section{Introduction}

Education is the social activity of cultivating people (Zhu, 2001). At present, school education has become an important part of education, and the curriculum is the main way in school education. The purpose of the curriculum is to spread and develop the cultural knowledge system of human beings to the next 
generation, so as to equip them with the cultural knowledge they need to enter the society in the future and form correct values and attitudes towards life. The curriculum is also a social phenomenon, a process of constant change, a product of a certain historical society, and it must also reflect the basic requirements of a specific period and a specific society for the development of human beings. The changes in the curriculum will first be reflected in the changes in the curriculum objectives. The basic education in China has made important improvements. The curriculum objectives have gone from "double-base" (basic knowledge and basic skills) to "three-dimensional goals" (knowledge and ability, process and method and emotional attitude value) to "the transformation of the curriculum objectives under the guidance of core literacy. Each of the curriculum reform will have a profound impact on teaching methods and learning evaluation."

After the reform and opening-up, China's economy, science and technology, and culture have flourished, and all walks of life need a large number of talents with solid scientific knowledge and labor skills. In this special background, the "double-base" curriculum (basic knowledge and basic skills) was unanimously approved by the society (Hu \& Wang, 2018). However, in actual teaching, the status of knowledge and skills is not equal. The "double-based" curriculum objectives emphasize the important role of knowledge and ignore the role of skills. With the development of society, especially for full-deepening surface development of human cognition, people are increasingly concerned about the emotional development of students, and "double-base" curriculums are unable to adapt to a new era for integrated talent demand (Hu \& Wang, 2018).

At the beginning of the $21^{\text {st }}$ century, China launched a new round of basic education reform, expounding the objectives of the "three-dimensional" curriculum. This is the first time that "process and method, emotional attitude and value" has been put forward as an important dimension of student development from the macro perspective of national curriculum reform. The "three dimensional" curriculum emphasizes not only "changing the tendency of the curriculum to pay too much attention to knowledge imparting, but also the formation of a proactive learning attitude. Only in this way can students learn to study and form correct values while acquiring basic knowledge and skills. However, "three-dimensional goal" can't make "students as the main body" education concept of the implementation of the cultivation of students' innovation ability is still weak. With the increasingly intensified international competition, all walks of life are in urgent need of innovative talents in the new era, thus putting forward new requirements for educational reform (Nan et al., 2019).

In March 2014, the Ministry of Education of China issued the "Opinions on Comprehensively Deepening the Reform of Curriculum Implementation and Implementing the Fundamental Tasks of Moral Education”, linking core literacy with deepening curriculum reform. As the DNA of curriculum reform, the concept of "core literacy" is not accidental. It is rooted in the history of the traditional "competency-based" education reform, aiming at correcting the educa- 
tional bias of too much emphasis on knowledge and ability and too little attention on attitude (Zuo, 2016). In February 2016, in the "China Student Development Core Literacy (Draft for Comment)" issued by the China Education Association, the content of core literacy was further defined academically. The solicitation draft pointed out that core literacy is a must-have character and key ability that students gradually adapt to the needs of individual lifelong development and social development in the process of accepting the corresponding paragraphs of education. The value of core literacy is to cultivate a "comprehensive person" that includes three dimensions. First, self-development (cultivating physical, psychological, and learning literacy); second, social participation (handling the relationship between individuals and groups, society and the state); third, cultural literacy, mastering the various achievements of human wisdom and civilization.

The goal of the course is the starting point and destination of the course design and implementation. It not only restricts the direction of curriculum design, but also serves as the basis for selecting and organizing the course content, and is also a reference for formulating the curriculum evaluation criteria. Core literacy is the latest research result of China's basic education curriculum reform. The previous curriculum implementation methods can't be adapted to this change, and the new curriculum implementation program is still constantly explored in practice. This article will review the characteristics of curriculum implementation under the guidance of "double-base" curriculum objectives and "three-dimensional objectives", and take the mathematics discipline of Jinhua Foreign Language School in Zhejiang province as an example to introduce the beneficial experience of curriculum reform under the guidance of core literacy curriculum objectives.

\section{The Connotation of Mathematics Core Accomplishment}

The definition of core accomplishment in China is as follows: it mainly refers to the necessary character and key ability that students should have to adapt to the needs of lifelong development and social development. To be specific, the core quality defined by China is "all-round development of people" as the core, which is divided into "cultural basis", "independent development" and "social participation", which is comprehensively manifested in six qualities: cultural background, scientific spirit, learning, healthy life, responsibility, practice and innovation. The core accomplishment of students' development proposed by the ministry of education is the combination of students' knowledge, skills, emotion and attitude, which is the value direction of talent cultivation. On the one hand, the core accomplishment transcends the framework of discipline division and is the implementation of the fundamental task of "cultivating people through virtue". However, on the other hand, the formation of the core accomplishment is inseparable from the subject knowledge, so the subject accomplishment is the concrete implementation of the core accomplishment. Starting from the implementation of the fundamental task of "cultivating people by virtue", the core ac- 
complishment of mathematics will become the most important purpose and goal of the reform of mathematics curriculum, and it is the necessity of the transformation of teaching and learning methods of the mathematics curriculum.

Mathematical discipline accomplishment means that students can develop mathematical abstraction, logical reasoning, mathematical modeling, intuitive imagination, mathematical operation, data analysis and other mathematical core accomplishments in the process of learning and applying mathematics. The first three qualities are the reflection of the basic characteristics of mathematics, that is, mathematics has abstractness, logical rigor and extensive application. The last three core qualities reflect the three learning fields of figures and geometry, Numbers and algebra, and statistics and concepts respectively (Rui et al., 2019). The mathematics course based on mathematics core accomplishment should highlight three things: first, it should be consistent with mathematical laws and clear structure; second, it should highlight the essence of mathematics; third, it should be easy to transform into mathematics core accomplishment.

\section{Exploration of Mathematics Curriculum Reform under the Guidance of Core Quality}

The implementation of the mathematics curriculum is the systematic planning and arrangement of mathematics teaching activities and plays a leading role in mathematics classroom teaching. The mathematics teaching design based on the core literacy of mathematics disciplines is the key to whether mathematics teaching can implement the core literacy of mathematics. We will start from the main part of mathematics teaching design and take the mathematics teaching reform of Jinhua Foreign Language School in Zhejiang Province as an example. We also combine with the teaching case analysis and do some discussion on how to implement core literacy mathematics teaching.

\subsection{Constructing Teaching Objectives Based on Core Literacy}

Education is a kind of social activity for cultivating people. Educating people is an essential feature. The basic means of education is teaching. In teaching, we should first make clear what the teaching goal is, namely, what kind of psychological traits we want to cultivate students. Teaching objectives will not only restrict the design of teaching process, but also affect the choice of teaching methods. It is also an important basis for teaching evaluation.

As far as the specific teaching objectives are concerned, teachers should analyze the core literacy of mathematics disciplines included in the mathematics lesson in this section after studying the textbooks and combining their position and role in the mathematics knowledge system. However, the content of the textbook does not necessarily reflect the corresponding core accomplishment of the subject, it may involve a variety of core accomplishment of the subject (Jin, 2019). This requires teachers to sort out the core qualities contained in the content of the textbook, distinguishing the important from the secondary (Yan, 
2019).

Secondly, the core of mathematics literacy is abstract. However, teaching goals should be a specific, clear, workable and can inspection in addition to emotional goals. This puts high demands on the professional quality of teachers. Teachers need to transform the core literacy contained in the teaching content into explicit teaching goals (Yao \& Guo, 2018).

Finally, teachers need to understand the relationship between core literacy and three-dimensional goals. Core literacy is not a negation of three- dimensional goals, but further refinement and integration of them. The three- dimensional goal is to achieve a core literacy path. In short, core literacy is a superior concept, which is proposed to cultivate a comprehensive talent of the information society in the new era. It must rely on teaching to implement core literacy. Teaching must clarify teaching objectives, and teaching objectives must respond to core literacy.

\subsection{Improve the Effectiveness of Teaching Process Based on Core Quality}

The teaching process is the means to achieve the teaching objectives. To some extent, the effectiveness of the teaching process directly determines whether the teaching objectives can be achieved. In the past, teachers paid more attention to the "double-base" (i.e., basic knowledge and basic skills). It is far from enough that the mathematics teaching under the guidance of core literacy only pays attention to the double foundation. Some scholars have proposed that mathematics teaching under the guidance of core quality should focus on "four bases" and "four abilities". The "four bases" are the basic knowledge, basic skills, basic ideas and basic experience of activities. "Four abilities" refers to the ability to find and present mathematical problems, analyze and solve them. Teachers must implement the requirements of "four bases" and "four abilities" in the process of designing teaching activities (Yan, 2019). For example, when the students learn the word problem "distance-speed-time", the basic knowledge is the conceptual and logical relationship of the three. The basic idea and basic activity experience are to establish a connection between students' life experience and current learning knowledge, to deeply understand the relationship between speed, distance and time, and to have a profound understanding of the idea of "equivalence relationship" in word problems. "Four abilities" requires students to be able to solve problems in life based on what they have learned. For example, the ability to infer travel times for a given location based on the speed differences between different vehicles, and determine which vehicles are more cost-effective based on the cost of transportation.

\subsection{Changing Teaching Methods Based on Core Literacy}

Teaching method is the way that teachers present the teaching content. Teaching methods and teaching objectives are closely related to educational philosophy. Under the guidance of the "double-base" teaching objectives, teachers are re- 
quired to lead, and the main body of the students mainly adopts the teaching method; the "three-dimensional goal" teaching goal emphasizes the student-oriented inquiry learning. However, with the continuous advancement of basic education reform, it is still difficult to achieve a "life-oriented" education concept. Teaching under the guidance of core literacy will change the way of teaching and achieve a life-oriented approach.

Cooperative inquiry learning is an important teaching method to implement the core literacy goal (Korkeamäki \& Dreher., 2012). Cooperative inquiry learning is better than learning alone. At the group level, it aims to promote inquiry learning at the individual level by fostering the spirit of cooperation between students and people to promote social development and critical questioning. However, cooperative learning and inquiry learning are not separated, but a whole, which is integrated. It is inseparable to explore cooperation and cooperate in inquiry. For example, when learning the basic principle of the shortest line segment between two points in the geometry, the teacher presents a real-life problem: there are two villages on the bank of the river, and it is necessary to build an irrigation hydropower station along the river. The problem is what is the shortest path to connect the two sides. Students work together to draw construction drawings and work out plans and reasons for construction through discussion. Students make auxiliary lines through exploration to draw the junction point, determine the site selection of hydropower station, and can better understand the shortest line segment between two points (Han \& Shin., 2009).

\subsection{Improve the Evaluation Mechanism Based on Core Literacy}

Learning evaluation is a process in which teachers collect information in a classroom through measurement or non-measurement, judge and make decisions about students' learning status, and develop a teaching plan that is most suitable for student development (Lin, 2016). The development of learning evaluation experiences traditional patterns, dynamic assessments, and curriculum-based evaluation models. The traditional model is guided by behaviorism and early cognitive psychology, often using standardized norm reference tests. The purpose of using traditional assessments by school staff is to answer several questions: What are the characteristics of students in learning? What level of development is his basic ability? What are his strengths and weaknesses? How can we help students make progress in their future studies? How is the student's progress? Based on the evaluation results of the traditional model, school officials can make relevant educational decisions, such as assigning students to classes and determining the strengths and weaknesses of students in certain skills development. Palinscar et al. (1991) proposed a dynamic assessment to overcome the rigid tendency of traditional assessments. Dynamic evaluation is not just a simple pre-test and post-test, but a continuous process. The evaluation needs to be integrated with the teaching and can directly guide the teaching. Dynamic evaluation is not to determine what students have learned, but to as- 
sess the level of students' ability to learn in a teaching context. As a result, the importance of standardized tests has declined and informal evaluations have been elevated to significant positions. For example, the student's learning process is evaluated based on the student's learning process. Therefore, dynamic evaluation has great flexibility and continuity. The course-based evaluation is based on the content of the course and uses a standard reference test to assess the mastery of the student's specific knowledge and skills that are closely related to the teaching (So, 2009). Since the standard reference evaluation does not consider the completion of tasks by other individuals, it is a self-reference evaluation and an effective supplement to the traditional evaluation model. It brings teaching to the most prominent position, focuses on the course objectives, and reduces the role of tests and exams. For example, the teacher plans to teach students to read and write 100 Chinese characters within a month. At the end of the month, students will be evaluated for their mastery of 100 Chinese characters.

Core literacy is a response to the needs of the comprehensive talents of the new era (Xin et al., 2014). The past three learning evaluation models cannot meet this requirement. In the 1980s, on the basis of the reflection and criticism of the evaluation of traditional reward and punishment learning, the University of Open Education Institute of the United States, Natoll and Clift, proposed a new type of evaluation method and concept-developmental learning evaluation. Developmental learning evaluation should provide learners with selectable diversity evaluation goals and evaluation indicators, and dynamically generate personalized evaluation criteria according to the learner's choices, so as to achieve individualized evaluation of learners (Yang, 2014). At present, the vigorous development of big data and wisdom education has made it possible for developmental evaluation, and developmental evaluation is an important evaluation method to achieve the core literacy goal of mathematics (Calfee et al., 2014).

\section{The Change of Teaching Mode Based on Core Literacy}

\section{1. "Double-Master" Teaching Mode}

The "Double-master" teaching mode refers to the teaching mode under the guidance of modern educational thought and teaching theory, which takes teachers and students as the main body at the same time. Teachers are responsible for formulating teaching objectives, designing teaching situations, guiding learning methods and guiding students' personality development (Feng et al., 2014). The emphasis on the guidance of the teacher-led teaching mode needs teachers to focus on the key content. Taking students as the main body means that students are the main subjects of learning in teaching activities, and students should actively learn according to their learning plans and cognitive levels. Teachers need to mobilize students' initiative and enthusiasm in the learning process. The learning plan and learning situation require the design of teachers. The results of learning and education are ultimately reflected in students. This requires teachers to design and adjust the teaching procedures from the needs of 
students, so that teaching is more in line with the needs of students and suitable for the development of students. Therefore, teachers' dominance and students' subjectivity need to be integrated.

\section{2. "Life-Oriented" Classroom Inquiry Mode}

With the deepening of educational reform, the consensus of current teaching thought is that students are the foundation and the teaching content is determined by students' learning level (Hong, 2012). In classroom teaching, the concept of taking students as the foundation has completely changed the teaching mode dominated by teachers in the traditional education. If we can design the teaching content from the perspective of students and fully abide by the rules of quality education, we can improve students' initiative and learning ability. The core of teaching is to teach the "learning method". The key to teaching is to cultivate students' ability to learn and explore independently.

Mathematics learning is a process of students' active observation, comparison and discovery of teaching. It requires teachers to fully embody the "life" teaching ideas in classroom teaching, mobilize students' subjective initiative, encourage students to think positively and explore independently. Students will gradually learn to acquire new knowledge through practice, feel the charm of mathematics class, and improve classroom teaching efficiency. In specific teaching practice, teachers use questions to mobilize students' learning emotions, lead students to actively participate in classroom teaching, and let them quickly enter the best state of learning. Teachers need to guide students to think, analyze and solve problems in a spirit of inquiry, to create a relaxed, pleasant and democratic learning atmosphere. Teachers also need to let students draw conclusions and discover rules in the process of continuous observation and analysis, to maximize the "student-oriented" teaching philosophy (Shute et al., 2010).

\subsection{Self-Inquiry Mode Based on Practical Experience}

The goal of talent training in the new century is to cultivate students' ability of sustainable development (Park, 2008). Sustainability means having a solid foundation, staying power, and space for growth. Therefore, it is required to not only teach students knowledge, but also develop students' intelligence, cultivate students' independent inquiry ability, but also teach students the method of learn-

ing. Teachers should encourage students to take the initiative to participate in, willing to explore, diligent in practice, let students have the initiative to learn. When teachers train students to participate in the learning process, they should not only make students learn knowledge, but also cultivate students' self-learning ability, enthusiasm and innovation. In the classroom teaching to establish the development of students as the fundamental concept of education, to improve students' learning ability as their responsibility, so that students fully understand the knowledge in practice.

Faced with the globalization of knowledge development and scientific and 
technological activities, the competition for talents is becoming increasingly fierce. In the early 1980s, some education experts pointed out that "students are the main body of education", which caused a great discussion in the educational field. In the past 20 years of educational reform practice, the subject education has become the trend of educational improvements. It has become the consensus of the majority of educators and some experience has been gained to establish the modern education concept with subject education as the core, to emphasize the subjectivity of people, to attach importance to the development of people, and to reform the unreasonable behavior mode and thinking mode in the original traditional education. As an important part of the basic education reform, mathematics curriculum reform must meet the needs of The Times.

\section{Conclusion}

With the continuous advancement of China's basic education reform, as an important carrier of education, curriculum reform is an important focus of education reform. Taking the mathematics discipline of Jinhua foreign language middle school in Zhejiang province as an example, this paper introduces the beneficial exploration of the curriculum reform of mathematics subject under the guidance of core quality. First, in terms of the setting of teaching objectives, teachers should study the textbooks and determine the observable and testable teaching objectives by comparing the core qualities. Second, in the process of mathematics teaching, teachers should pay special attention to students' mastery of "four bases" and "four abilities" under the guidance of core literacy. Third, in terms of teaching methods, teachers should pay more attention to the teaching methods of cooperative inquiry, give full play to students' autonomy and promote social development. Finally, in terms of learning evaluation, it advocates the developmental evaluation, especially the developmental evaluation supported by big data, which may be a more appropriate evaluation method to assess whether students have acquired the core literacy.

\section{Acknowledgements}

I am grateful to Jinhua Foreign Language School for embracing this research.

\section{Conflicts of Interest}

The author declares no conflicts of interest regarding the publication of this paper.

\section{References}

Calfee, R., Wilson, K. M., Flannery, B., \& Kapinus, B. A. (2014). Formative Assessment for the Common Core Literacy Standards. Teachers College Record, 116, n11.

Feng, L., Min, Z., \& Bin, Z. (2014). Curriculum Development Based on Curriculum Standards. Chinese Education Journal, No. 2, 63-66.

Han, C. H., \& Shin, B. S. (2009). Possibility of Social Studies Curriculum via Core Com- 
petencies. Korean Journal of Social Studies Education, No. 4, 123-144.

Hong, W, P. (2012). An International Study of the Changing Nature and Role of School Curricula: From Transmitting Content Knowledge to Developing Students' Key Competencies. Asia Pacific Education Review, 13, 27-37. https://doi.org/10.1007/s12564-011-9171-Z

Hu, H.-X., \& Wang, Z.-J. (2018). The Evolution Research of Educational Objectives in the Concept of Core Competencies. Contemporary Education and Culture, 10, 56-63.

Jin, Y.-Q. (2019). Higher Vocational Mathematics Curriculum Reform Based on Cultivation of Core Quality. Chinese Vocational and Technical Education, No. 20, 38-42.

Korkeamäki, R. L., \& Dreher, M. J. (2012). Implementing Curricula That Depend on Teacher Professionalism: Finnish Preschool and Early Childhood Core Curricula and Literacy-Related Practices. European Early Childhood Education Research Journal, 20, 217-232. https://doi.org/10.1080/1350293X.2012.681128

Lin, C. D. (2016). A Study on Students' Development of Core Literacy in the 21st Century. Education Science Forum, No. 20, 24.

Nan, H., Tong, S., \& Xu, Y. (2019). Cultivation of Students' Core Literacy Based on the Mathematical Culture Perspective. East Asian Mathematical Journal, 35, 163-172.

Rui, N., Li, C.-Y., \& Luo, Z.-X. (2019). The Structure of Mathematical Core Competencies and Its Teaching Significance. Journal of Mathematics Education, 28, 24-29.

Palinscar, A. S., Brown, A. L., \& Campione, J. C. (1991). Dynamic Assessment. In H. L. Swanson (Ed.), Handbook on the Assessment of Learning Disabilities (pp. 75-94). Austin, TX: Pro-Ed.

Park, M. J. (2008). A New Approach to Curriculum Development in Higher Education: Competency-Based Curriculum. Korean Journal of Curriculum Studies, No. 4, 173-197.

Shute, V. J., Masduki, I., \& Donmez, O. (2010). Conceptual Framework for Modeling, Assessing and Supporting Competencies within Game Environments. Technology, Instruction, Cognition \& Learning, 8, 137-161.

So, K. H. (2009). Curricular-Historical Base and Its Liberal Nature of Competency-Based Education. Korean Journal of Curriculum Studies, 27, 1-20.

Xin, T., Jiang, Y., \& Wang, Y.-H. (2014). Curriculum System Constitution Based on Students' Key Competencies. Journal of Beijing Normal University, No. 1, 5-11.

Yan, J.-Y. (2019). Research on Mathematics Teaching Design Based on Core Literacy of Discipline. Contemporary Education and Culture, No. 9, 1-5.

Yang, X.-M. (2014). The Connotation and Characteristics of Wisdom Education in the Information Age. China Electrification Education, No. 1, 29-34.

Yao, J. X., \& Guo, Y. Y. (2018). Core Competences and Scientific Literacy: The Recent Reform of the School Science Curriculum in China. International Journal of Science Education, 40, 1913-1933. https://doi.org/10.1080/09500693.2018.1514544

Zhu, X.-M. (2001). On the Subjective Constructiveness of Education and Pedagogy. Theory and Practice of Education, No. 9, 1-5.

Zuo, H. (2016). The International Trend of the Curriculum Reform of Basic Education: Go Towards Core Literacy. Curriculum, Teaching Material and Method, 36, 39-42. 